\title{
Burocracia partidista: la profesionalización legislativa de los Senadores en México
}

Party bureaucracy: the legislative professionalization of Senators in Mexico

Jaime Espejel Mena

Universidad Autónoma del Estado de México - México

Estado de México, México

jespejelm@uaemex

\section{RESUMEN}

La relación entre la burocracia partidista y la profesionalización, en particular del senado de la república en México, se puede explicar desde el enfoque de sistemas, como una relación causal y formal. No obstante, para explicar el ejercicio de la dominación propia del poder político precisa algo más que hechos, la eficiencia es también resultado de sentimientos y anhelos de los ciudadanos. En este sentido, la presente investigación sugiere desde el enfoque del institucionalismo histórico, que el conflicto entre la burocracia partidista producido por la escasez de recursos, se centra en la política y se expresa en sus candidaturas para integrar la cámara de senadores. Para ello, las instituciones oscilan entre las reglas de un orden constitucional o de los procesos operativos de una burocracia y los acuerdos que predominan en el comportamiento entre las asociaciones informales. El objetivo del presente documento es explicar que la profesionalización de los órganos legislativos depende de la actividad propia de los congresos como profesión, del conocimiento personal de los legisladores y del desempeño institucional de los órganos legislativos como resultado de su profesión y profesionalización. Concluimos planteando que el grado de burocratización y el tipo de liderazgo burocrático al interior de los partidos políticos retarda o motiva los procesos y consenso político necesarios para consolidar la profesionalización de la política y en particular de la profesionalización del senado de la república.

Palabras clave: Burocracia; partido político; profesionalización; senadores; México. 
The relationship between partisan bureaucracy and professionalization, particularly in the Mexican Senate, can be explained from the systems approach, as a causal and formal relationship. However, to explain the exercise of the proper domination of political power requires more than facts, efficiency is also the result of feelings and wishes of citizens. In this sense, the present research suggests from the perspective of historical institutionalism, that the conflict between the party bureaucracy produced by the scarcity of resources, focuses on politics and is expressed in their candidacies to integrate the Senate. For this, the institutions oscillate between the rules of the constitutional order or the operational processes of a bureaucracy and the agreements that predominate in the behavior among informal associations. The objective of this document is to explain that the professionalization of legislative bodies depends on the activity of congresses as a profession, on the personal knowledge of legislators, and on the institutional performance of legislative bodies as a result of their profession and professionalization. We conclude by stating that the degree of bureaucratization and the type of bureaucratic leadership within the political parties' retards or motivates the processes and political consensus necessary to consolidate the professionalization of politics and in particular the professionalization of the Senate of the Republic.

Keywords: Bureaucracy; political party; professionalization; senators; Mexico.

\section{Introducción}

Algunos factores que hacen explícita la apertura de los gobiernos hacia las demandas sociales, son las siguientes. En primer lugar, depende de cómo se compongan los altos niveles de la burocracia, qué valores predominen en el seno de la comunidad política, y la pluralidad de la clase política que toma las decisiones. En segundo lugar, del marco normativo para la toma de decisiones, las habilidades y competencias de los responsables de diseñar políticas eficientes, y una correlación entre las demandas de la sociedad civil y el cambio organizacional de la estructura administrativa. Con respecto a este elemento, el tipo de medio ambiente impulsa el cambio organizacional en virtud de que éste es inducido desde el exterior del sistema. Bajo esta lógica, las organizaciones que sobreviven a las presiones del medio ambiente se deben a la calidad y cantidad de sus recursos. En contraparte, las organizaciones cuya autonomía del sistema es relativa, son menos susceptibles a condiciones externas, al igual que a las oportunidades de cambio. En tercer lugar, de la relación entre las autoridades políticas y las estructuras administrativas, máxime porque la relación no siempre es simétrica ya que a veces un mismo agente cumple más roles (Morlino, 1985).

Esto puede también aplicarse a los subsistemas del gobierno. Si son relativamente independientes es posible que se vean menos afectados por influencias externas, lo cual no necesariamente limita su capacidad de cambio. Si la estructura gubernamental -en un sentido amplio- tiende a ser estática y conservadora, el grado de autonomía de un subsistema puede afectar favorablemente a su capacidad relativa para el cambio (Rustow, 1992).

El grado del cambio externo inducido, también está determinado por la naturaleza del medio ambiente. Diversos esfuerzos se han realizado para clasificar los medios ambientes 
organizacionales (Mintzberg, 2002), de manera particular resaltamos la importancia de aquellos medios que contienen elementos comunes y que no son mutuamente excluyentes.

Partimos del supuesto de que los problemas de gobernabilidad que enfrenta nuestro gobierno y la fragilidad de la democracia tienen su origen en la llamada crisis de partidos políticos, desde el momento en que dichas organizaciones han dejado de dar respuesta eficiente y procesar las demandas que la sociedad le hace al Estado. Abordamos las ideas desde la perspectiva del nuevo institucionalismo, donde privilegiamos la relación de las estructuras, instituciones y agencias (Alcántara, 2011). Los cambios institucionales son producto de un cambio en los actores, en la socialización y en la propia cultura; es decir, en el ambiente, en la cultura y en los valores, respectivamente. El presente documento considera que los problemas de esclerosis que enfrentan los gobiernos y la fragilidad de la democracia tienen su origen en la llamada crisis de gobernabilidad, desde el momento en que las organizaciones públicas dejan de dar respuesta eficiente y procesar las demandas que la sociedad le hace al Estado. Abordamos las ideas desde la perspectiva del institucionalismo, donde privilegiamos la relación de las estructuras, instituciones y procesos. Los cambios institucionales son producto de un cambio en los actores, en la socialización y en la propia cultura, es decir, en el ambiente, en la cultura y en los valores, respectivamente (Dimaggio, y Powell, 1999). Cuando las normas, reglas, productos y valores de las acciones del gobierno no tienen una fuente legal o institucional clara, la legitimidad institucional de éstas queda a expensa de la eficiencia política y administrativa, toda vez que la racionalidad y legitimidad no se fundan en circunstancias instituyentes, sino instituidas e impuestas por las organizaciones cambiantes.

El documento concluye planteando que la burocracia partidista e incluso su élite y clase política, son fenómenos que permiten explicar el escaso profesionalismo, cuestión que explica la gobernabilidad de nuestra democracia (Lindau, 1993). La crisis de gobernabilidad se gesta, sobreviene y desarrolla desde el momento en que dichas instituciones no cumplen a cabalidad con su función, y a esto hay que agregar lo desgastado de los ingresos del Estado, el aumento considerable de la corrupción y su corolario, que se expresa en el deterioro general de las mismas instituciones y de los niveles de vida, así como de las expectativas (Alcántara, 2012, 2013).

\section{Metodología}

La investigación observa, desde un análisis institucional, que los mecanismos formales que regulan la burocracia partidista y los actores que hacen que funcione el senado de la república mexicana responden a principios de eficiencia y eficacia propios de la economía global y nacional, de esta manera la administración pública es definida como in instrumento técnico. Queda desprovista de un enfoque teórico que sustente su función política y social. Desde el enfoque del institucionalismo histórico se acepta el argumento de que el conflicto entre camarillas, producido por la escasez de recursos, se centra en la política; pero a la vez, busca indagaciones para distinguir los resultados políticos y las desigualdades que señalan los resultados. Para ellos, las instituciones oscilan entre las reglas de un orden constitucional o de los procesos operativos promedio de una burocracia y los acuerdos que predominan en el comportamiento entre las asociaciones formales.

No se presenta un estudio de caso a manera de tipos ideales, se abordan las peculiaridades de la investigación científica desde un conjunto de evidencias comunes, desde la comparación de las estructuras y procesos del Estado mexicano, que se aplican para asegurar la estabilidad y 
orientación política, económica y social de los procesos de dominación (Almond y Powell, 1972). A través del enfoque institucional, se reflexiona sobre la estructura partidista y la profesionalización del senado de la república en México a través de la revisión de las variables nivel educativo y experiencia legislativa.

Las variables burocracia partidista y la profesionalización legislativa son provistas de un contexto histórico y social para explicar su encuentro con el poder público y desencuentro con la democracia (Blau \& Meyer, 1971). No se hace uso de datos estadísticos como instrumento de análisis, se desprende que en México las formas de dominación dependen de su contexto histórico y regional, a partir de las maneras en que se imponen, negocian o reconcilian los diferentes grupos. Con la presencia de una vasta normatividad formal se supondría que la dominación de la burocracia es racional legal, no obstante, la observación del régimen informal sugiere lo contrario.

\section{Desarrollo}

\subsection{Gobierno y calidad de la política}

Hoy en día la necesaria institucionalización de la calidad de la política reclama de la innovación en algunas facetas de la vida humana, la cual se está ampliando considerablemente o se constituye como una norma constante de los gobiernos, que se enfrentan con las necesidades de adaptar sus estructuras a nuevas condiciones, demandas y oportunidades. Este asunto adquiere particular importancia por los constantes cambios que se presentan en la sociedad actual y sus efectos sobre las organizaciones cuya contingencia conlleva hacia la complejidad. Lo anterior se ha convertido en una categoría significativa para el análisis de las relaciones entre una organización y el mundo externo: la organización del gobierno y de sus instituciones se ven también afectadas por ella (Valencia, 2014).

El cambio y el conflicto se han vuelto algo común en gran parte de las naciones, incluyendo las no occidentales. En el actual periodo de la historia, caracterizado por un constante proceso de democratización, el gobierno y sus instituciones constituyen un factor constante y dominante en la sociedad nacional e internacional. Como consecuencia, la participación del gobierno y la estructura burocrática han constituido un factor crucial en el control de esta contingencia y una determinante fundamental de la legitimidad del gobierno. Esta participación también significa que las instituciones deben reajustarse a las condiciones cambiantes, a las demandas y a las oportunidades, que varían drásticamente de un país a otro y que dependen de los sistemas sociales y políticos vigentes y del nivel de desarrollo nacional (Montaño, 2017).

La gobernabilidad como coherencia y flexibilidad política, requiere de varios momentos, demanda de una legitimidad institucional y de una eficiencia política y administrativa. El ejercicio de la dominación propia del poder político, sujeta a la valoración de los ciudadanos a sus instituciones, a sus integrantes y a sus resultados. La satisfacción o insatisfacción institucional, política y administrativa se puede trasladar a la evaluación de la vida democrática.

En diversas funciones del proceso de conversión, el gobierno desempeña un papel central: sus subsistemas se incluyen en estas funciones en diversos grados. Los insumos internos son aspectos importantes del proceso. Las salidas se realizan a través de procesos de conversión: estas pueden ser las iniciativas de ley sometidas a consideración del Congreso o Parlamento, decisiones 
ejecutivas, reglas y reglamentos, programas gubernamentales, mecanismos y reglamentos para el control y manejo de fuerzas sociales para el mantenimiento de los servicios de seguridad y orden público (Barzelay, 2000). Para estos casos debe hacerse una distinción entre las salidas formales y las informales. Las primeras incluyen decisiones conocidas, las segundas los efectos que estas decisiones tienen en la realidad. Las salidas de los subsistemas del gobierno son similares a las mencionadas previamente, pero también incluyen proposiciones y servicios a otras partes de la estructura: propuestas del gabinete, decisiones del ejecutivo del Estado o decisiones de los especialistas de los procesos gubernamentales (Easton, 2012).

Se ha planteado que las demandas efectuadas por el medio ambiente -bien sean explicitas o implícitas-, así como los procedimientos e interacciones con la estructura gubernamental, pueden crear tensiones que den origen a una demanda y a la modificación de las estructuras y los procesos. Esto se aplica también a los subsistemas de la estructura. Las salidas que están dirigidas hacia la reorganización de estructuras y procesos se convierten en respuesta, o en desidia, de diversas partes o unidades de la estructura gubernamental y de los individuos incorporados a la organización.

Dos factores principales, en la relación sistema-medio ambiente, codeterminan los efectos del medio ambiente en las estructuras y procesos organizacionales del gobierno: el grado de apertura de la estructura gubernamental y el tipo de medio ambiente.

Respecto al primer elemento, éste nos permite observar en qué medida el cambio espontáneo o inducido de estructuras y procesos del gobierno son provocados o influidos por el medio ambiente. Esto es determinante en la medida en que los miembros o grupos inmersos en la estructura gubernamental, busquen y detecten señales del medio ambiente que sean relevantes para la propia estructura del gobierno. Al considerar los aspectos que se abren en las organizaciones e instituciones del gobierno, se devela un tema que ha sido tradicionalmente estimado como una debilidad fundamental de las burocracias políticas, sobre todo por su desinterés hacia las necesidades de la comunidad política. Este tipo de relación entre la sociedad y el gobierno causa importantes inercias para caracterizar cuándo las estructuras del gobierno son cerradas o abiertas (Montaño, 2018).

El ejercicio de la dominación propia del poder político precisa algo más que hechos, la eficiencia es también resultado de sentimientos y anhelos de los ciudadanos. En suma, es pertinente la necesidad de una estrategia sustantiva de planeación y ejecución de la eficiencia política y administrativa al interior y exterior de la estructura gubernamental. Los cambios y reformas improvisadas e incoherentes, pueden resolver necesidades urgentes y temporales, pero representan respuestas vulnerables a la debilidad fundamental del sistema y desatienden las propiedades sistemáticas de la estructura gubernamental. Es decir, la medición de la profesionalización (Patrón y Camacho, 2018) depende de los niveles en la que se mide la misma, la profesionalización legislativa puede ser considerada una variable continua o discontinua.

\subsection{La calidad política y la acción de gobierno}

El cambio y la transformación son inseparables de la naturaleza del individuo. Los contextos políticos, sociales, económicos y culturales con los que nació la administración pública clásica en el Estado de Bienestar ya no son los mismos. Hoy en día la eficiencia y eficacia política, como 
fuente de generación y regeneración del Estado, es pieza clave en la forma de llevar la nueva gestión pública. A pesar de los constantes cambios la administración pública perdura con otros principios y otras formas de operar, pero se mantiene intacta la necesidad de una fuente de legitimación y su proceso de gobernar (Arenilla, 2010).

En un primer momento, fueron relevantes los elementos estructurales de las organizaciones del gobierno, la eficiencia política se basaba en una eficiencia jurídica, la administración pública en buena medida cumplía sus funciones de vinculación y articulación social, a través de la atención de los viejos y nuevos problemas sociales con un mínimo de impuestos y con una política social fuerte. Los cambios en la estructura y en el poder, como producto de las funciones que se le atribuía a la administración pública, fueron legalizados o formalizados. Los procedimientos se establecían con el ánimo de reglamentar y formalizar las estructuras e instrumentos legales, para proteger al ciudadano y a las instituciones de violaciones o abusos de poder (Blanco y Gomà, 2002).

En su momento la eficiencia política del Estado de Bienestar no basto con circunscribirse a las esferas de acción y comportamiento que recoge explícitamente del marco institucional formal. Buena parte de la administración pública, en efecto, atañe a actividades que con frecuencia escapan a los diversos planteamientos tradicionales de las ciencias administrativas o jurídicas. Se comenzó a suponer que suele haber presente en todo gobierno capacidades y acciones para resolver un sinnúmero de conflictos de interés que surgen dentro del ámbito del sistema político. Las causas de la crisis del viejo Estado de Bienestar adquirieron consenso, a ello contribuyeron las crisis financieras, la crisis del petróleo y los duros programas presupuestarios de la década de los setenta (Arenilla, 2011).

La eficiencia política, en la gestión pública, tiene su fuente de legitimidad en el reconocimiento público, más que al apego formal o al esquema constitucional. El apoyo del ciudadano a un Estado, en buena medida, es resultado de un desempeño eficiente y eficaz, cuando se reduce la desigualdad, la pobreza, se fortalece el Estado democrático y la ciudadanía a través de la prestación de servicios, leyes, acciones y es complementado cuando el público observa que el desempeño de las decisiones es justo, es decir, cuando la gestión pública crea un valor (Barzelay, 2003). La corriente de la nueva gestión pública, pone el centro de atención de la eficiencia administrativa en el logro de resultados o en el mejor manejo de los asuntos públicos. La nueva gestión pública, la búsqueda de la calidad, la gobernabilidad o el cumplimiento de códigos de ética alimentan la reflexión sobre las instituciones públicas con la finalidad de que gocen de una mayor legitimidad y aceptación por los ciudadanos.

La base de la gestión pública es la eficiencia de resultados, la legitimidad se concreta con la evaluación de la gestión. Las prioridades ciudadanas determinan las acciones del gobierno, el cumplimiento de estas es medido periódicamente, la competitividad que demuestra el aparato público es necesaria para lograr la satisfacción del ciudadano. El binomio ciudadano-cliente es el que valida las acciones del gobierno. La administración pública es la gestora de las contradicciones que ocurren en su interior. La medición de los resultados y la satisfacción del ciudadano vienen a sustituir a la eficiencia legal-racional (Baena del Alcázar, 2010).

Se entiende por eficiencia política la aptitud, competencia o potencial de un gobierno para fijar directrices que conduzcan a objetivos considerados válidos por una sociedad en un momento 
determinado. A su vez, la capacidad administrativa, considerada como un caso particular o una derivación lógica de la primera; podría visualizarse como el potencial institucional y operativo que permite instrumentar los objetivos socialmente aceptados y jurídicamente consignados en la constitución política del Estado en cuestión (Peters, 2001),

En buena medida la autoridad de cualquier institución, como tan persuasivamente lo ha argumentado Max Weber, se basa a la postre en la creencia popular de legitimidad. Por ello los desafíos considerables y persistentes a la legitimidad de las instituciones gubernamentales deben verse con preocupación, pues amenazan con menoscabar la capacidad del gobierno. En este sentido, la legitimación de un Estado democrático se sustenta en su constitución política y el proceso político por el cual se renueva el poder político y su clase gobernante.

La calidad distintiva del Estado moderno consiste en que depende del proceso administrativo como instrumento principal para forjar la política nacional. No obstante, se pueden presentar las condiciones que creen y expliquen la instauración de dependencias u organizaciones para compensar las deficiencias institucionales en la formulación y administración de la propia política nacional. El que el proceso de gestión adquiera cierta autonomía, genera el riesgo de despersonalizar la responsabilidad política que adquieren los gobernantes, después de un proceso político democrático.

Instituciones, sistemas y estructuras desenvuelven su trayectoria en el ámbito de los poderes del Estado y de los ámbitos de gobierno. Esos son elementos que pueden definirse como la estructura del poder formal. A su vez, sobre esas jurisdicciones gravitan los partidos políticos y los grupos de interés que definen a la sociedad pluralista. Estos elementos forman la capa del poder informal que condiciona la provisión de insumos y la obtención de productos públicos. Instituciones, sistemas y estructuras aparecen entonces gobernados por superestructuras de poder piramidal, en ocasiones formal y preciso y en otra informal y difuso. Los agentes inteligentes de la organización administran a las células o subunidades de la propia organización; sobre su toma de decisiones gravitan, con mayor o menor notoriedad, las directrices de los secretarios, ministros o de los directores de los sistemas; en las subunidades pesan las orientaciones de los partidos a que pertenecen, la presión de los grupos y la opinión pública, las organizaciones religiosas o los militares.

La separación de poderes sigue abierta a controversia teórica como secuela de las prácticas constitucionales. En un primer momento representó un equilibrio entre la eficiencia política y la eficiencia administrativa: la acción pública quedaba sujeta, en última instancia, a la aprobación, interpelación o censura de los representantes del pueblo. Sin embargo, desde la aparición de los partidos políticos, el equilibrio quedó amenazado. En los regímenes presidenciales, el presidente trata de crear una imagen de independencia respecto de su fila partidista, aunque eso en ocasiones no resulta factible políticamente. Por su parte, los ministros y los legisladores no desdeñan esa línea que los mantiene entrelazados a su partido al tomar decisiones.

En tales circunstancias, no tiene sentido hablar del poder a través del consenso frente al poder a través de la administración; administra el partido político o la coalición en el poder y censura al que quedó en la oposición. Si el mismo partido del Ejecutivo domina el Congreso, éste no controla a aquél; si el partido político que integró al Ejecutivo es minoría en el Congreso, éste puede impedirle realizar una gestión con holgura. Esto es la historia cotidiana de la llamada división de 
poderes, en los países contemporáneos gobernados constitucionalmente. El hecho de que estos países sean los menos estudiados en la literatura de la ciencia política no oculta la realidad de que sean los más numerosos en escala mundial (Linz, 1996).

El proceso político está involucrado con el proceso administrativo. Resulta difícil concebir, aun en sistemas sociopolíticos con marcada diferenciación estructural, la total separación de funciones que implicaría la existencia de una administración pública estrictamente instrumental. Todo comportamiento administrativo lleva implícitas algunas derivaciones políticas y no se puede ignorar el hecho de que los grupos de presión que buscan el poder actúan con gran proximidad a los niveles decisorios de la administración pública. Más aun, puede afirmarse que las luchas que se liberan en el interior de la administración pública han pasado a constituir una forma principal de acción política (O’ Donell, 2009).

En las naciones de Occidente aún perdura la tesis de que la administración del Estado es moderna al estar organizada por el modelo racional-legal de Max Weber (2019). El detalle de esta apreciación es la correlación de una administración pública moderna con una sociedad industrializada y políticamente pluralista. Sin embargo, la rápida transformación económica encaminada a la industrialización, no exige como condicionante el ajuste de las estructuras administrativas a las normas derivadas del modelo neoweberiano. En lo político Samuel Huntington (2016) arguye que un sistema autocrático tiene mayores posibilidades de promover transformaciones económicas profundas a corto plazo que otro basado en la competencia política.

Una práctica constante en países en proceso de cambio político es la tendencia de las élites políticas a centralizar el proceso administrativo, utilizando a la administración como un instrumento para ejercer control sobre los gobiernos locales. En efecto, los regímenes contemporáneos, -con inestabilidad en sus procesos políticos, así como inestables en su economía- han tenido que promover transformaciones socioeconómicas a través del control férreo del proceso administrativo, es decir, dirigir la eficiencia decisional y su valor público (Huntington, 2016). En general, para las estructuras de un gobierno en transición el valor de la centralización del proceso político y administrativo siempre es mayor que la autonomía y búsqueda de consolidación de la eficiencia de los mismos (Nolte, 1991).

Es clásica la tesis que considera a la función pública como una fuente de voluntad política, tanto del representante como del administrador. El argumento de semejante aseveración radica en la condición múltiple del individuo frente a la política y a la administración pública, esto es, como integrante de la fuente de eficiencia política o como parte de la eficiencia administrativa. Verbigracia al realizar las tareas burocráticas cumple parte de un proceso administrativo y cuando ejerce un derecho o cumple una obligación de naturaleza política coincide o discrepa del grupo en el poder, al cual sirve.

En última instancia las instituciones formales aparecen como el instrumento asequible con el que los Estados modernos legitiman democráticamente su cotidiano quehacer social. La legitimidad institucional es condición indispensable de la eficacia institucional al dotar a éstas de una capacidad inherente de imponer obediencia y respeto. La legitimidad permite a una institución alcanzar sus metas sin la necesidad regular, de amenazar con el empleo de la fuerza y de crear episodios renovados de resentimiento público. 


\subsection{Eficiencia institucional en el gobierno: confianza y valor instituyente}

Las acciones que produce el gobierno no son acciones producto de una racionalidad lineal, incremental, total o limitada; por el contario son el resultado de un proceso de negociación constante entre actores públicos y privados, que intercambian recursos e información con el fin de influir en el resultado político y administrativo de los mismos.

Los sistemas administrativos, los aparatos burocráticos, los gerentes públicos, el servicio civil de carrera o el gobierno, son aparatos del Estado que pretenden crear y recrear la legitimación del mismo. La eficiencia, la legitimación, la legalidad, la funcionalidad o la racionalización administrativa, son algunas tendencias que habrán de lograrse con el adecuado actuar del Estado y su predominio en la actividad política. La legitimidad de los cambios en la estructura administrativa del Estado la otorgan los rápidos cambios sociales que se presentan, y no en la legalidad que éstos atiendan.

Las mutaciones de la comunidad-Estado, la integración de bloques económicos, el aumento de la desigualdad económica, la segregación cultural, la multiculturalidad de la sociedad, constituyen realidades que exigen la revaloración del Estado que conocemos. El paradigma de la elección racional (Buchanan y Tullock, 1993) los postulados de la teoría del Estado mínimo (Nozick, 1990) o el nuevo institucionalismo (March y Olsen, 1997) tienen la pretensión política de revalorar al Estado en un mundo incierto.

La tesis de Georg Sorensen (2011) es que se viven tiempos turbulentos como resultado de la conclusión de la Guerra Fría y la entrada a un contexto contingente en el que el Estado es testigo de realidades inéditas: terrorismo, lucha de identidades, globalización, regionalización, gobernance, redes sociales, redes de políticas, responsabilidad, transparencia y rendición de cuentas, buen gobierno, nueva soberanía, repliegue del Estado, integración económica y política, Estado postnacional, gobernanza democrática, liberalización, democratización. En este contexto, la administración del Estado también se va adaptando a nuevos ejes: 1) democratización de la administración, 2) relación principal agente, 3) visión de redes, 4) gestión y responsabilidad y 5) implementación de capacidades públicas (Uvalle, 2009).

El encuentro entre lo estable y continuo que caracteriza a la modernidad, y lo discontinuo y complejo que enmarca la posmodernidad, han confrontado a su realidad histórica emblemática: al Estado moderno. El encuentro entre el orden y el caos es contradictorio para el Estado, no existe un orden perfecto ni un desorden perfecto, el producto de la unión entre dos o más componentes es la complejidad que enfrenta el Estado. Ante estos acontecimientos es pertinente seguir preguntándonos ¿Cómo hacer frente a los constantes cambios que se presentan en las fuentes de legitimación política y administrativa del gobierno hoy en día?

Al respecto Charles Tilly (2010, p. 20), plantea que “la calidad de la política pública en un régimen u otro depende significativamente de las relaciones entre las redes de confianza básica de la gente y las estrategias de gobierno de los gobernantes”. La confianza -al igual que las redes de confianza- es consustancial a la legitimidad de las acciones del gobierno o de las políticas. Así, las políticas públicas son producto del consenso entre gobernantes, agentes gubernamentales, gobiernos, actores políticos y el régimen. 
A las políticas siempre subyace una pretensión de eficacia para la solución de problemas. No obstante, para que las políticas generen confianza en la esfera pública resulta ineluctable que sean conocidos los gobernantes o las autoridades elegidas; es indispensable que los agentes gubernamentales y actores políticos hablen en nombre del gobierno; y es crucial un papel protagónico de las entidades no gubernamentales. En este sentido, para crear una red de confianza en los resultados del quehacer del Estado la condición es que todos los agentes involucrados en las políticas trabajen de forma colaborativa.

El propio Tilly (2010), siguiendo a Adam Smith, sugiere que las redes de confianza en "países comerciales" funcionan por el parentesco, no obstante, las redes basadas sólo en el parentesco a medida que la civilización avanza, éstas se debilitan y dan paso a relaciones más complejas, como lo pueden ser las asociaciones políticamente activas o la incorporación y carrera de los miembros de la red en la administración pública. Los participantes en estas redes, obtienen beneficios personales y protección contra posibles eventualidades, ayudas que no podrán adquirir en otra parte. Los supuestos de la elección racional, de la teoría de juegos o del neo institucionalismo económico, están presentes en los análisis de Charles Tilly, ya que las redes, por un lado, son el resultado de cálculos individuales sobre los costos y beneficios, de las relaciones entre agentes y principales o de la disminución de los costos de transacción.

La revisión de las redes de confianza que Tilly propone, va más allá: permite distinguir entre las acciones gubernamentales -acciones de los agentes gubernamentales- y las acciones sociales -acciones de los actores políticos-. Las primeras son acciones del gobierno hacia la sociedad, mientras que las segundas van de la sociedad hacia el gobierno. Ambas acciones, por separado causan sospecha o ausencia de confianza. Las redes de confianza de la sociedad, al polarizarse, solo expresan y amalgaman ciertos vínculos, le causan sospecha al resto de la sociedad, y pueden llegar a conformar una acción colectiva que conforme un movimiento social.

Las conexiones entre la política pública y las redes de confianza varían. En un extremo las redes de confianza operan dentro del gobierno porque son unidades regulares que el propio aparato gubernamental conduce y determina. Por otro lado, las redes de confianza operan fuera del gobierno, fuera de la vista de éste, sin controles de vigilancia. Estas redes cambian de posición para acercarse o alejarse de la política pública, cuando la red de confianza vive bajo la protección de un intermediario, relativamente autónomo, esta puede alejarse de la sintonía del gobierno, por el contario cuando la red de confianza se conecta con el gobierno, puede ayudar a satisfacer las demandas que se realizan a las autoridades políticas.

Charles Tilly (2010: 52), sugiere la revisión de las redes de confianza, desde una forma de estructuralismo combinado, es decir, las estructuras no sólo se entienden y reproducen así mismas, son también producto de las interacciones de intercambio entre los individuos su “...enfoque invierte la dirección causal, tratando las actitudes no como causa, sino como efectos de la interacción social”. Un claro ejemplo de ello, es que la confianza puede incidir en la democratización, así como en la desconfianza de la misma. Los regímenes políticos y las redes de confianza enfrentan problemas comunes, afrontan dificultades organizativas en su funcionamiento interno, que se reflejan en su conservación y en la relación de uno y otro. Ambos dependen de estructuras, que los provean de nuevos recursos para su continuidad, que produzcan y reproduzcan sus principales actividades. 
De acuerdo a la estructura de las organizaciones, estás pueden funcionar por lo menos bajo tres esquemas:1) de forma autoritaria, 2) de manera cooperativa y3) a través de redes de confianza. Para Tilly en las redes de confianza, se valora de forma diferente el riesgo a largo plazo y se recuperan las condiciones de los seres humanos, es decir, las redes de confianza almacenan, producen y capitalizan las experiencias de la red. La participación individual o grupal en la construcción de infraestructura de la red contribuye a la creación y recreación del capital social. Por el contrario, cuando la política pública incentiva la desconfianza o cuando los procesos sociales determinan las relaciones humanas y se privilegien las fechorías, el capital social será nulo. "La larga historia que hemos investigado sugiere que, en la medida en que subsistan Estados de alta capacidad que recurran especialmente al capital y al compromiso como incentivos para la participación, también subsistirá la integración contingente de las redes de confianza a la política pública" (2010: 255).

La política pública contingente, no legítima a las acciones del gobierno, no genera capital social, no restablece la relación entre confianza-legitimidad-gobierno, no propicia redes de confianza, no genera instituciones, no crea valor instituyente.

En opinión de Claue Lefort (1990), la eficiencia política y administrativa no pueden ser reducidas a instituciones legales o mecanismos que legitimen la toma de decisiones por la mayoría o por la minoría en el gobierno. La idea y el contexto democrático de la legitimidad, presuponen y se legitiman frente a palabras como respeto a la individualidad, representación, instituciones, partidos políticos, participación, derechos humanos, tolerancia o soberanía. La idea sugiere el supuesto de que las instituciones democráticas, transparentes, legítimas u homogéneas subordinan al individuo a la cohesión social. La búsqueda de una legitimidad política y administrativa, a través de la defensa de la soberanía nacional, para mantener una armonía social, una defensa de los derechos y libertades individuales, queda inconclusa si ésta no es equivalente con el interés común, es decir, con la libertad política. Para Lefort (2007), la esencia de lo político se revela en la libertad individual y la libertad política, por el individuo y el ciudadano, por los valores civiles y cívicos. La integralidad del argumento es el fundamento último de la legitimidad en una democracia moderna.

Cuando las acciones humanas, se constituyen por experiencias basadas en la libertad individual y la libertad política se inicia una nueva aventura, una nueva forma de sentir y conocer, las certezas se matizan, el saber es puesto en tela de juicio. Se cuestiona la institucionalidad de la sociedad por una ley, por un poder o en un Estado. Surge una nueva idea, una nueva experiencia, nuevos principios que trascienden las costumbres, las tradiciones, la heterogeneidad que acompañan a la dominación del individuo por la ley, por la sociedad, por el Estado, por todas las organizaciones que imponen un valor instituido. La legitimación en una democracia moderna, se constituye como un proceso sin principio ni fin, la indeterminación de la legitimidad, se aleja de cualquier hecho empírico, de cualquier cuantificación de la satisfacción de demandas o del porcentaje del cumplimiento de ciertas obligaciones.

La determinación de la sociedad, la sociedad con historia, la sociedad con referentes únicos, las determinaciones de los hechos empíricos reducen a la democracia a un totalitarismo. La indeterminación del poder exalta a la libertad individual y la libertad política, preserva el cuestionamiento a toda explicación única de la legitimación: en la democracia moderna la legitimación nace en cada acto, no puede ser reducida a hechos políticos, administrativos, 
económicos, culturales, sociales, o de otro tipo. Para Claude Lefort (2007), la legitimación es una mutación de orden simbólico, un espacio que nadie puede ocupar una sola vez o para siempre. La legitimación, es una circunstancia que es inaugurada con la democracia moderna, a principios del siglo XIX, la democracia más que una forma de gobierno es una forma de sociedad. Según Lefort, el gran reto de la sociedad democrática es la disolución de las certezas, el derrumbe de los indicadores que determinan al hombre con buena o mala conducta. La democracia conduce al individuo, lo alienta, lo somete al desafío de crear sus propios fundamentos que reconocen su propia institución: en este caso la democracia. Los fundamentos de la democracia, presentan rasgos fundacionales que la hacen indeterminable, la incertidumbre es inherente a toda forma de sociedad democrática. La democracia y su legitimación tienen un orden simbólico, un orden político, que se hace y rehace por los individuos.

Ninguna verdad, ninguna justificación es inmutable, toda vez que el origen del poder habrá que pensarse, porque ya no pertenece a alguien. El poder pertenece a la sociedad democrática, el poder es potencialmente de todos y no puede ser personificado por algún sujeto o grupo (Maestre, 1994). El poder es un lugar vacío, que no se puede ocupar por una sola persona, es un lugar simbólico que solo ocupa y controla el sufragio. En lo paradójico del argumento, en la indeterminación última, en la disolución de las certezas, radica el fundamento del poder. Por el contario, cuando el poder toma cuerpo, cuando la búsqueda de la verdad es sustituida por la verdad, cuando el pueblo es sustituido por el profeta, cundo el poder se constituye en algo particular al servicio de unos cuantos, la democracia se asume como totalitarismo.

La rendición de cuentas, la transparencia, la legitimidad, la legalidad, habrá que repensarlas en su valor cívico, en su carácter y naturaleza fundacional de la constitución de los derechos políticos como derechos del hombre, es decir, no como acciones o políticas del gobierno, más aún como inherentes a la forma de sociedad, como partes de una cuestión social. En una sociedad democrática, los derechos humanos aparecen ligados a una concepción integral de la sociedad, no son sólo derechos individuales, derechos naturales, derechos sociales, derechos del ciudadano, derechos constitucionales o garantías individuales, se trata de derechos que expresan la dignidad del hombre, de derechos políticos, que, al ponerse en cuestionamiento, se cuestiona la forma de sociedad.

El argumento de Claude Lefort (2004), rechaza la idea de que los derechos humanos sean reducidos a derechos individuales, ya que la naturaleza del individuo es constitutiva a la forma de sociedad, los derechos del hombre definen y valoran al tipo de régimen.

El significado político de los derechos del hombre, es lo que diferencia a un régimen totalitario de uno democrático ya que la naturaleza política de las sociedades democráticas, le confieren la responsabilidad generadora de la democracia a los derechos del hombre. Los derechos del hombre son generadores de la democracia, porque en ellos se amalgama la materialización jurídica, que regula el comportamiento de los individuos y el afecto, la adhesión que se provoca entre los hombres. La relación entre la institucionalización del derecho y las conciencias de los hombres, es una relación problemática y por demás compleja, es una relación que adquiere la forma de régimen político. 


\subsection{Burocracia partidista, gobierno y profesionalización de la política}

Max Weber (2019) mostró que, en la medida en que toda relación real de dominación implica un mínimo de voluntad de obedecer, era importante analizar situaciones concretas, singulares y situadas históricamente para comprender estos intereses especiales de obedecer, las acciones individuales adquieren un sentido social y permiten comprender el tipo de dominación, principalmente en términos políticos. Las relaciones de poder, en su opinión, se encuentran dentro de los conflictos, compromisos, arreglos y, en general, relaciones sociales: la dominación y la disciplina no pueden por tanto ser aprehendidas fuera de su ejercicio. Estas interdependencias están situadas históricamente y, por lo tanto, comprender el poder requiere que comprendamos funciones concretas, relaciones y relaciones concretas. Las prácticas concretas de la burocracia partidista juegan un papel activo en las relaciones de poder y en la profesionalización de sus elites y afiliados. La concepción de hegemonía de Antonio Gramsci, que no es solo coerción, sino también una forma de gestión cultural e ideológica que surge del poder de las relaciones, luchas sociales, negociaciones, compromiso, cooptación, representaciones y creencias compartidas (Hibou, 2020), también pueden explicar las acciones de los órganos legislativos. Es decir, la burocracia partidista no es un fenómeno natural, está íntimamente ligada al gobierno. La creación de medidas legislativas y procedimientos administrativos se lleva a cabo por el gobierno, estas pueden crear o eliminar los obstáculos para la profesionalización de la política y de la tarea legislativa.

La clasificación de la profesionalización de la política y los políticos profesionales se ponen de manifiesto en los procesos de democratización o desafección a la democracia (Morlino, 2009). La evaluación de la política y el actuar de sus actores es un proceso inherente de la institucionalización de la eficiencia y la confianza. La burocracia partidista entendida como la difusión de prácticas burocráticas procedentes del tipo de organización e intereses propios del partido político condicionan las formas de educación de sus simpatizantes y la profesionalización de sus políticos. La burocracia partidista es difusa y fragmentaria, no es un dispositivo administrativo, una institución o una estructura organizativa, es una forma social de poder, un movimiento social que instituye su poder en la sociedad (Hibou, 2020). Contrariamente su desarrollo y funcionamiento depende de actores que, conscientemente o no, realizan procesos comprometidos o manipulados con una racionalidad técnica. La comunicación de lo político es instituida y camina entre la libertad y la dominación de la sociedad.

Desde la óptica de los neoinstitucionalistas históricos el propósito de su enfoque es especificar la relación entre la institución y la acción. Por ello, se explican que las instituciones son resistentes al rediseño institucional, ya que estructuran las propias elecciones sobre la reforma que el individuo pretenda promover.

Una segunda característica del análisis en el institucionalismo histórico se refiere al papel preponderante concedido al poder y a sus relaciones; de ahí que todos los estudios neoinstitucionalistas tienen un tratamiento central sobre ese tema, sobre todo, en la manera en que las instituciones distribuyen el poder entre los grupos sociales. Por ello, en vez de considerar escenarios predeterminados para reclutar a los individuos, los institucionalistas históricos son proclives a suponer que hay un mundo en el cual las organizaciones dan incentivos a los grupos para su acceso al proceso de toma de decisiones (Powell \& Dimaggio, 1991). 
Esta corriente, por otro lado, está relacionada con una perspectiva del desarrollo histórico a partir del concepto de casualidad social, en el sentido de que deja de lado el principio en que las fuerzas operativas generan resultados similares en las fuentes organizacionales. En cambio, favorecen la perspectiva de que el efecto de esas fuerzas será medido por los signos contextuales de una situación específica, naturalmente institucional. Por ello, las organizaciones son tomadas como elementos relativamente persistentes del panorama histórico y como uno de los factores centrales que llevan al desarrollo histórico mediante un conjunto de rutas incrementales, en periodos de continuidad, pero puntualizados por coyunturas criticas cuando un cambio institucional se realiza. Los institucionalistas históricos otorgan una importante atención al papel de las instituciones en la vida política, pocas veces insisten en que las organizaciones son la única fuerza causal en la política. Pretenden centrar a las organizaciones en una cadena causal que incorpora un papel relativo a otros factores, especialmente en términos de desarrollo político y de difusión de ideas. Como eje central, estos institucionalistas dan por sentado que el mundo es más complejo que el mundo de preferencias e instituciones, a menudo postulado por los institucionalistas de la elección racional. Desde esta perspectiva, difícilmente la profesionalización legislativa dependerá de los políticos y estará sujeta a las relaciones políticas y de poder de la propia estructura formada a lo largo de la historia (March y Olsen, 1997).

\subsection{El Senado en México: la LXIV Legislatura de la República}

La legitimidad institucional de un Estado se logra principalmente a través de la forma de gobierno representativo, adoptado por las democracias contemporáneas, -especialmente aquel que nace de un cambio violento o de una transición política- consolida su legitimación sociohistórica en la medida que va traduciendo en realidades los objetivos que recoge en su plataforma ideológica, y éstos se establecen como medios para resolver las demandas populares que le dieron origen (Cabezas, 2012). Este conjunto de objetivos implica a su vez la designación de instrumentos de acción o agentes que promuevan el cambio o el orden político, económico, social y administrativo, que deben orientarse a la traducción operativa de las metas que constituye el proyecto de nación; que generalmente es recogido por la constitución o instituciones formales de cada país (Alcántara y Cabezas, 2013).

En el caso de México, la Cámara de Senadores está conformada por 128 integrantes, está se elige a través de tres principios de elección: 64 senadores electos de manera directa; 2 por cada una de las 32 entidades federativas que integran el país; 32 senadores asignados a la primera minoría, es decir el segundo lugar de la elección, esto es uno por cada entidad federativa y 32 senadores que son electos según el principio de representación proporcional, mediante el sistema de una lista nacional, de acuerdo al porcentaje de votación obtenida en el país. La Cámara de senadores en la LXIV legislatura, está integrada por 6o representantes del Partido Movimiento Regeneración Nacional (MORENA); 25 del Partido Acción Nacional (PAN); 12 del Partido Revolucionario Institucional (PRI); 8 de Movimiento Ciudadano (MC); 6 del Partido del Trabajo (PT); 6 del Partido Verde Ecologista de México y 4 del Partido Encuentro Social (PES). En la fichas curriculares que se presenta en el portal del Senado de la República se manifiesta que de los 60 senadores del grupo parlamentario de MORENA 32 carecen de algún tipo de experiencia legislativa, de los 25 Senadores del PAN 8 se manifiestan sin experiencia, los 12 Senadores del PRI presentan algún tipo de experiencia, los 4 representantes de Movimiento Ciudadano no tienen experiencia legislativa, 
de los 6 Senadores del PT, 6 del PVEM y 4 del PES, se manifiestan 2, 4 y 3 Senadores sin experiencia respectivamente (Tabla 1).

Tabla 1 Integración de la LXIV Cámara de Senadores

\begin{tabular}{|c|c|c|c|c|}
\hline \multirow{2}{*}{ 1) Partido Político } & \multicolumn{3}{|c|}{ 2) Tipo de elección } & \multirow{2}{*}{ 3) Sin experiencia } \\
\cline { 2 - 5 } & Mayoría relativa & $\begin{array}{c}\text { Representación } \\
\text { proporcional }\end{array}$ & Primera minoría & \\
\hline MORENA & 39 & 11 & 10 & 32 \\
\hline PAN & 8 & 6 & 11 & 8 \\
\hline PRI & 1 & 5 & 6 & 0 \\
\hline $\begin{array}{c}\text { Movimiento } \\
\text { Ciudadano }\end{array}$ & 4 & 2 & 2 & 4 \\
\hline PT & 5 & 1 & 0 & 4 \\
\hline PVEM & 1 & 3 & 2 & 3 \\
\hline PES & 1 & 3 & 0 & 2 \\
\hline
\end{tabular}

Fuente: Senado de la república (2021).

La profesionalización de la Cámara de Senadores, se explica en el presente documento, a través del grado de escolaridad y trayectoria o experiencia legislativa. En el total de senadores encontramos 18 doctores, 26 maestros y 59 licenciados, de los 128 senadores solo 103 cuentan con alguna habilitación académica.

Los estudios de doctorado con la mayor recurrencia son: Derecho, ciencia política, economía y educación. Dentro de las Maestrías con la mayor frecuencia se encuentran: Administración pública, administración de empresas, derecho y educación. Las licenciaturas con mayor presencia están entre: Derecho, contaduría, economía y computación. Los estudios que presentan condiciones únicas son el Doctorado en ciencias de lo fiscal, la Maestría en programación neurolingüística y la Licenciatura en teatro. Si bien la escolaridad o profesión no es requisito para participar en el cargo, tampoco podemos negar que el entrenamiento formal, la generación de habilidades y capacidades es mayor cuando la especialización en un área del conocimiento es mayor (Patrón y Camacho, 2018), en el caso mexicano el partido político MORENA saca ventaja de la formación académica de sus candidatos. La formación académica adquiere un sentido significativo cuando observamos la integración de las Comisiones parlamentarias con mayor frecuencia, dentro de estas destacan: Derechos humanos, agricultura, ganadería, pesca y desarrollo rural, comunicaciones y transportes y hacienda y crédito público. La tarea legislativa está orientada a la discusión de los derechos humanos, los recursos naturales, las comunicaciones y transportes y marginalmente a la hacienda.

El aprendizaje del trabajo parlamentario a través de la experiencia legislativa no es menos indicativo, 28 de los 60 senadores de MORENA desempeñaron con anterioridad algún cargo de representación popular, ya sea como Diputados locales o federales, como Senadores o Gobernadores o presidentes municipales. Del PAN 17, del PRI 12, 4 de Movimiento Ciudadano y del PT, 2 del PVEM y 1 del PES (Tabla 2). 
Tabla 2 Burocracia partidista

\begin{tabular}{|c|c|c|c|c|c|c|c|}
\hline \multirow{2}{*}{$\begin{array}{l}\text { 1) Partido } \\
\text { Político }\end{array}$} & \multirow{2}{*}{ 2) Senador } & \multicolumn{3}{|c|}{ 3) Nivel educativo } & \multirow{2}{*}{$\begin{array}{l}\text { 4) Experiencia (Senador, } \\
\text { Diputado, Gobernador o } \\
\text { presidente municipal) }\end{array}$} & \multicolumn{2}{|c|}{ 5) Género } \\
\hline & & Licenciatura & Maestría & Doctorado & & M & H \\
\hline MORENA & 60 & 24 & 12 & 12 & 28 & 29 & 30 \\
\hline PAN & 25 & 14 & 7 & 2 & 17 & 14 & 11 \\
\hline PRI & 12 & 5 & 2 & 3 & 12 & 5 & 7 \\
\hline $\begin{array}{c}\text { Movimiento } \\
\text { ciudadano }\end{array}$ & 8 & 4 & 3 & 1 & 4 & 3 & 5 \\
\hline PT & 6 & 3 & 2 & 0 & 4 & 4 & 2 \\
\hline PVEM & 6 & 5 & 0 & 0 & 2 & 3 & 3 \\
\hline PES & 4 & 4 & $\mathrm{O}$ & 0 & 1 & 4 & 0 \\
\hline
\end{tabular}

Fuente: Senado de la república (2021).

La burocracia partidista y la profesionalización de la política y del trabajo legislativo mantienen una relación causal, la candidatura a una senaduría está determinada por la estructura burocrática del partido y solo de manera marginal por la trayectoria académica y la experiencia en el trabajo legislativo. La calidad de la política al no fundarse en una profesionalización queda a expensas de la valoración del actuar de los partidos políticos. Es decir, la confianza en el trabajo de los Senadores sigue siendo la fuente del valor instituido y no instituyente de una institución (Lefort, 1990).

\section{Conclusiones}

La actividad que desarrolla el senado de la república no es solo una función política o jurídica, el senado juega un papel preponderante dentro del sistema político mexicano. Sus funciones forman parte del conjunto institucional del gobierno, en el que convergen las demandas de los ciudadanos, las autoridades gubernamentales, los representantes del órgano legislativo y de forma indirecta la estructura burocrática de los partidos políticos (Jiménez y Solano, 2017).

El estudio sobre la profesionalización de la política se ha centrado en las conductas de los presidentes, ministros, legisladores o jueces, en los principales actores y líderes de los partidos políticos, el resultado es la percepción social de malas prácticas, corrupción, dispendio, abuso de poder y enriquecimiento ilícito.

El representante del ejecutivo en las entidades federativas no se preocupa por las posibles decisiones de los legisladores de su propio partido debido a que el congreso local es sólo una etapa de la trayectoria política de sus cuadros. El rol del legislador no es una tarea a desarrollar sino un espacio funcional de reclutamiento político y formación de cuadros para la administración estatal o municipal. El tema de la profesionalización legislativa es un tema que está acompañando a la alternancia política y algunos cambios en el sistema de partidos, es el caso del oscilamiento entre un partido político hegemónico y uno predominante. 


\section{Referencias}

Alcántara Sáez M. y Cabezas Rincón, M. L. (2013). Estrategias electorales y funcionamiento interno de los partidos políticos: selección de candidatos y programas electorales. En M. Alcántara Sáez y M. L. Cabezas Rincón, (Eds.), Selección de candidatos y elaboración de programas en los partidos políticos latinoamericanos, (pp. 19-42). Tirant lo Blanch.

Alcántara Sáez, M. (2011). Gobernabilidad, crisis y cambio. FCE.

Alcántara Sáez, M. (2012). El oficio de político. Tecnos.

Alcántara Sáez, M. (2013). De políticos y política: profesionalización y calidad en el ejercicio público.

Perfiles latinoamericanos, 21 (41). https://www.redalyc.org/articulo.oa?id=11525601007

Almond, G., y Bingham Powell, G. B. (1972). Política comparada. Paidós.

Arenilla Sáez, M. (2010). La administración pública entre dos siglos. INAP.

Arenilla Sáez, M. (2011). Crisis y reforma de la administración pública. Netbiblo.

Baena del Alcázar, M. (2010). Manual de ciencia de la administración. Síntesis.

Barzelay, M. (2000). Atravesando la burocracia. Una nueva perspectiva de la administración pública. FCE.

Barzelay, M. (2003). La nueva gestión pública. Un acercamiento a la investigación y al debate de las políticas. FCE.

Blanco, I., y Gomà, R. (2002). Gobiernos locales y redes participativas. Ariel.

Blau, P., \& Meyer, M. W. (1971). Bureaucracy in modern society. Randon House.

Buchanan, J., y Tullock, G. (1993). El cálculo del consenso. Planeta-Agostini.

Cabezas Rincón, L. M. (2012). Profesionalización de las élites legislativas en Bolivia, Colombia, Ecuador y Perú, Tesis Doctoral, España, Salamanca, Universidad de Salamanca.

Dimaggio, P.J.y Powell, W.(1999). Introducción. EnW. Powell y P. Dimaggio (Comps.), Elnuevo institucionalismo en el análisis organizacional, (pp. 33-75). FCE.

Easton, D. (2012). Esquema para el análisis político. Amorrortu.

Hibou, B. (2020). La burocratización del mundo liberal. Dado.

Huntington, S. (2016). El orden político en las sociedades en cambio. Paidós

Jiménez Badillo, M., y Solano Ramírez, G. (2017). Perfil político-profesional de los legisladores en el Congreso de Guerrero. En M, Montaño Reyes y F. Patrón Sánchez. (Coords.), Élites parlamentarias locales en México. Actitudes y desempeño, (pp. 277-311). Tirant lo Blanch.

Lefort, C. (1990). La invención democrática. Nueva visión.

Lefort, C. (2004). La incertidumbre democrática. Ensayos sobre lo político. Anthropos.

Lefort, C. (2007). El arte de escribir y lo político. Herder.

Lindau, J. (1993). Los tecnócratas y la elite gobernante mexicana. Joaquín Mortiz.

Linz, J. (1996). La quiebra de las democracias. Alianza.

Maestre, A. (1994). El poder en vilo. Tecnos.

March, J., y Olsen, J. (1997). El redescubrimiento de las instituciones. La base organizativa de la política. Colegio Nacional de Ciencias Políticas y Administración Pública-FCE.

Mintzberg, H. (2002). La estructuración de las organizaciones. Ariel.

Montaño Reyes, M. (2018). La evaluación a los políticos: los legisladores de Italia, España, México y Argentina. Instituto Electoral del Estado de México.

Montaño Reyes, M. (2017). Introducción. En Montaño Reyes, M. y Patrón Sánchez, F. (Coords.), Élites parlamentarias locales en México. Actitudes y desempeño. Tirant lo Blanch.

Morlino, L. (1985). Cómo cambian los regímenes políticos. Centro de Estudios Constitucionales. 
Morlino, L. (2009). Democracias y democratizaciones. Centro de Investigaciones Sociológicas

Nolte, D. (1991). Procesos de descentralización en América Latina: enfoque comparativo. En Detlef Nolte (Ed.), Descentralización política y consolidación democrática. Europa-América del Sur, (pp. 73-88). Nueva sociedad.

Nozick, R. (1990). Anarquía, Estado y utopía. FCE.

O’ Donell, G. (2009). El Estado burocrático autoritario. Prometeo.

Patrón Sánchez, F. y Camacho García, Ma O. (2018). La profesionalización legislativa en México. Tirant lo Blanch.

Peters, G. (2001), La política de la burocracia. FCE.

Rustow, Dankwart A. (1992). Transiciones a la democracia. Hacia un modelo dinámico. En Merino Huera, M. Cambio político y gobernabilidad, (151-178). CNCPyAP-CONACYT.

Senado de la república (2021). Integración de senadores por orden alfabético, disponible en https://www. senado.gob.mx/64/senadores/por_orden_alfabetico

Sorensen, G. (2011). La transformación del Estado. Más alla del mito del repliegue. Tirant lo blanch.

Tilly, Ch. (2010). Confianza y gobierno. Amorrortu.

Uvalle Berrones, R. (2009). Condiciones, procesos y tendencias de la administración pública contemporánea. Convergencia, 16, 49. 73-102.

Valencia Escamilla, L. (2014). De la profesión a la profesionalización de los legisladores en México. UAM.

Weber, M. (2019). Economía y sociedad. FCE.

\section{AUTOR}

Jaime Espejel Mena. Doctor en Administración Pública. Es profesor de tiempo completo en el Centro Universitario Zumpango de la Universidad Autónoma del Estado de México. Sus líneas de investigación actual son: Gobierno y gobernabilidad urbana y gobernanza y redes de política pública.

\section{Conflicto de intereses}

Jaime Espejel Mena informa ningún conflicto de interés posible.

\section{Financiamiento}

No hubo asistencia financiera de partes externas al presente artículo.

Agradecimientos

N/A 